\title{
Characterization and Corrosion Behaviour of Selected Duplex Stainless Steels in Acidic and Acidic-Chloride Solution
}

\author{
Oluwatoyin Adenike Olaseinde ${ }^{1}$, Joasias Van der Merwe ${ }^{2}$, Lesley Cornish ${ }^{2}$ \\ ${ }^{1}$ Department of Metallurgical and Materials Engineering, Federal University of Technology, Akure, Nigeria \\ ${ }^{2}$ School of Chemical and Metallurgical Engineering, University of Witwatersrand, Johannesburg, South Africa \\ Email: adenikeseinde@yahoo.com
}

Received August 15, 2013; revised September 15, 2013; accepted September 22, 2013

Copyright (C) 2014 Oluwatoyin Adenike Olaseinde et al. This is an open access article distributed under the Creative Commons Attribution License, which permits unrestricted use, distribution, and reproduction in any medium, provided the original work is properly cited. In accordance of the Creative Commons Attribution License all Copyrights (C 2014 are reserved for SCIRP and the owner of the intellectual property Oluwatoyin Adenike Olaseinde et al. All Copyright (C) 2014 are guarded by law and by SCIRP as a guardian.

\section{ABSTRACT}

The 2101, 2205 and 2507 are duplex stainless steels. They have two phases: austenite and ferrite. The metallurgical characterization was performed by means of Scanning Electron Microscopy (SEM) with EDX and X-ray diffractometry (XRD). The corrosion behaviour was evaluated by potentiodynamic tests. The corrosion tests were conducted with the aid of potentiostat. The SEM and XRD revealed phases of austenite and ferrite without any intermetallic phase. The elemental analysis of the phases showed that the elements partitioned more into the phases that they promoted. The corrosion resistance of 2507 was higher than 2205 and 2101 as it may be seen on the polarization curves. Comparing the two media, the following relation to their corrosion resistance: $2507>$ $2205>2101$ was established.

\section{KEYWORDS}

\section{Duplex Stainless Steels; Potentiodynamic Tests; Characterization}

\section{Introduction}

Duplex stainless steels (DSS) have two phases, ferrite and austenite in almost equal proportion. The two phases' structure is very dependent on their composition and thermal history. Duplex stainless steel is employed in chemical, petrochemical, nuclear, marine and paper industry due to its excellent mechanical and good corrosion performance [1]. It offers a combination of properties, such as particularly good corrosion resistance in hot corrosion environments containing-chloride ions, mechanical strength and ductility, abrasion resistance, and weldability [2,3]. The commercial production of duplex stain-less steels started in about 1937 [4].

These alloys possess superior weld ability and better mechanical properties than austenitic stainless steel. Duplex stainless steel is about twice as strong as regular austenitic or ferritic stainless steel. However, they are more susceptible than austenitic steels to precipitation of phases causing embrittlement. They have better tough- ness and ductility than ferritic grades, although they do not reach the high values of austenitic grades.

After melting, duplex stainless steels solidifies from the liquid phase to a completely ferritic structure. As the materials cool, about half the ferritic grains transform to austenitic grains. In the solution of annealed condition (at about $1000^{\circ} \mathrm{C}$ ) [5], decomposition of the ferritic phase may lead to higher hardness, yield stress and ultimate tensile strength, although this decreases ductility and toughness. The partitioning of the alloying elements between the two phases and microstructures helped to understand the corrosion phenomenon of the alloys. The chemical composition of each phase may vary as the annealing temperature varies. The contents of $\mathrm{Cr}$ and Mo may change slightly in the ferrite phase because they are ferrite formers and partitioned more into that phase. The nitrogen concentration in the austenite phase may decrease with temperature as the volume fraction of austenite increases. This could lead to increasing pitting corro- 
sion resistance of duplex stainless steel. Chromium and Mo enrichment can occur in the ferrite phase, while $\mathrm{Ni}$ and $\mathrm{N}$ may concentrate in austenite phases [6].

This article reports the effect of composition and microstructure on the corrosion behaviour of the samples in sulphuric acid and sulphuric acid with chloride environment.

\section{Experimental}

The metallurgical characterization was performed by means of Scanning Electron Microscopy (SEM) and Xray diffractometry (XRD). The chemical composition of ferrite and austenite were determined by means of energy dispersive spectrometry (EDS) with the quantitative measurements performed with a standard less ZAF correction. The austenite content was measured by quantitative metallography using a grid. Electrochemical etching was done in $40 \mathrm{~g}$ of $\mathrm{NaOH}$ in $100 \mathrm{ml}$ distilled water to reveal the microstructures, the etchant coloured ferrite dark [7].

The response of these alloys in sulphuric acid and sulphuric acid with chloride solutions were evaluated by the potentiodynamic tests. The duplex stainless steels samples are the working electrodes which were embedded in epoxy resin. Prior to each experiments the working electrode was wet ground mechanically using successive grade emery papers from 350 to 800 grit to avoid crevice corrosion, the interface between specimen and resin was sealed with special silica gel sealant and dried in air. The exposed electrode 4 surface area was $10 \mathrm{~mm}^{2}$. All potentials recorded were measured with respect to saturated calomel electrode (SCE), the counter electrode was graphite. The corrosion tests were performed in naturally aerated $1 \mathrm{M} \mathrm{H}_{2} \mathrm{SO}_{4}$ aqueous solution with two different concentration of sodium chloride $(0,0.1 \% \mathrm{Cl})$. The polarization curves were performed with potentiostat equipped with GPES 4.19 software. The scan rate was $0.001 \mathrm{~V}$. The test solutions were $1 \mathrm{M} \mathrm{H}_{2} \mathrm{SO}_{4}$ and $1 \mathrm{M}$ $\mathrm{H}_{2} \mathrm{SO}_{4}$ with $1 \% \mathrm{NaCl}$. The solutions were made from analytical grade reagents and distilled water. All the electrochemical tests were performed at constant temperatures; water bath was used to control the temperature. All the experiments were performed in triplicate and good reproducibility were observed.

\section{Results and discussion}

\subsection{Metallography}

Three experimental alloys (2101, 2205 and 2507) were used, the alloy composition are shown in Table 1 . The molybdenum (Mo) content was higher in 2507 and was lowest in 2101. Higher Mo and Cr content was seen in 2205 and 2507 than 2101.

The percentage of ferrite was estimated by quantitative analysis using grid (Table 2). The volume fraction showed that all the duplex stainless steel understudy had austenite: ferrite ratio between $70: 30 \%$ which is acceptable for duplex stainless steel. The 2507 had an almost $50: 50$, austenite:ferrite ratio which is very beneficial to the microstructure and corrosion resistance of 2507. It was observed that the almost equal volume fraction helps in improving the corrosion resistance of duplex stainless steel [1].

The concentrations of major elements in ferrite $(\alpha)$ and austenite $(\gamma)$ phase analyses by EDX are listed in Table 3.

It is clearly shown that alloying elements such as $\mathrm{Cr}$ and Mo enrich in ferrite phase while Ni concentrate in austenite phase. These have also been reported [8,9].

Figures 1-3 show the X-ray diffraction patterns of the duplex stainless steel samples. The peaks corresponding to austenite and ferrites were identified. The pattern from the as-received sample 2101 is shown in Figure 1. XRD showed that the 2101 DSS sample was composed of ferrite and austenite. The strongest $\mathrm{X}$-ray peaks were those of ferrite. This is a good pattern with low background. Figure 2 presents the XRD pattern for 2205 duplex stain-

Table 1. Composition of the Duplex stainless steels (Iron is balance).

\begin{tabular}{cccccc}
\hline \multirow{2}{*}{ Alloy } & \multicolumn{5}{c}{ Element (wt\%) } \\
\cline { 2 - 6 } & $\mathbf{C r}$ & $\mathbf{N i}$ & $\mathbf{M n}$ & $\mathbf{N}$ & $\mathbf{M o}$ \\
\hline 2101 & $21.5 \pm 0.7$ & $1.5 \pm 0.3$ & $4.8 \pm 0.0$ & $0.2 \pm 0.0$ & $0.5 \pm 0.5$ \\
2205 & $22.5 \pm 0.7$ & $5.5 \pm 1.4$ & $2.0 \pm 0.0$ & $0.2 \pm 0.0$ & $3.3 \pm 0.4$ \\
2507 & $25.0 \pm 1.4$ & $7.0 \pm 1.4$ & $1.2 \pm 0.0$ & $0.3 \pm 0.1$ & $4.0 \pm 1.4$ \\
\hline
\end{tabular}

Table 2. Volume fraction (\%) of phases in duplex stainless steels.

\begin{tabular}{cccc}
\hline Alloys & $\mathbf{2 1 0 1}$ & $\mathbf{2 5 0 7}$ & $\mathbf{2 2 0 5}$ \\
\hline Ferrite $(\boldsymbol{\alpha})$ & $51.2 \pm 5.9$ & $49.3 \pm 4.6$ & $31.2 \pm 5.2$ \\
Austenite $(\gamma)$ & $48.8 \pm 5.9$ & $50.7 \pm 4.6$ & $68.8 \pm 5.2$ \\
\hline
\end{tabular}

Table 3. Composition of alloying elements in ferrite and austenite phases obtained by EDS (Iron is balance).

\begin{tabular}{ccccccc}
\hline \multicolumn{2}{c}{ ssD esahP } & iN & rC & nM & oM & iS \\
\hline \multirow{2}{*}{2101} & $\boldsymbol{\alpha}$ & $1.9 \pm 0.1$ & $22.2 \pm 0.1$ & $5.0 \pm 0.1$ & $0.3 \pm 0.0$ & $1.0 \pm 0.1$ \\
& $\gamma$ & $2.5 \pm 0.2$ & $20.6 \pm 0.0$ & $5.8 \pm 0.1$ & $0.0 \pm 0.0$ & $0.8 \pm 0.0$ \\
& $\boldsymbol{\alpha}$ & $4.2 \pm 0.3$ & $25.3 \pm 0.4$ & $1.7 \pm 0.2$ & - & $0.3 \pm 0.1$ \\
& $\boldsymbol{\gamma}$ & & & & & \\
& & & & & \\
2507 & $\boldsymbol{\alpha}$ & $5.8 \pm 0.3$ & $20.6 \pm 0.4$ & $3.04 \pm 0.4$ & - & $0.3 \pm 0.1$ \\
& $\gamma$ & $8.6 \pm 0.1$ & $24.8 \pm 0.4$ & $0.9 \pm 0.0$ & $2.8 \pm 0.1$ & $0.4 \pm 0.0$ \\
\hline
\end{tabular}




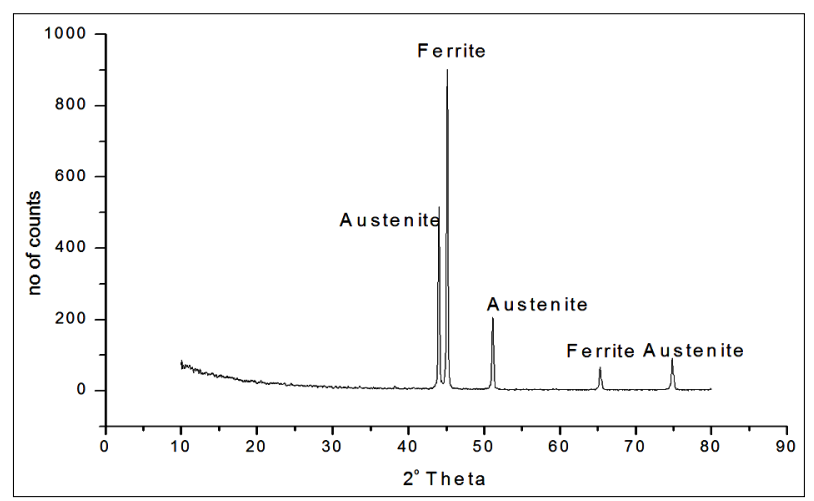

Figure 1. X-ray diffraction pattern of 2101 duplex stainless steel.

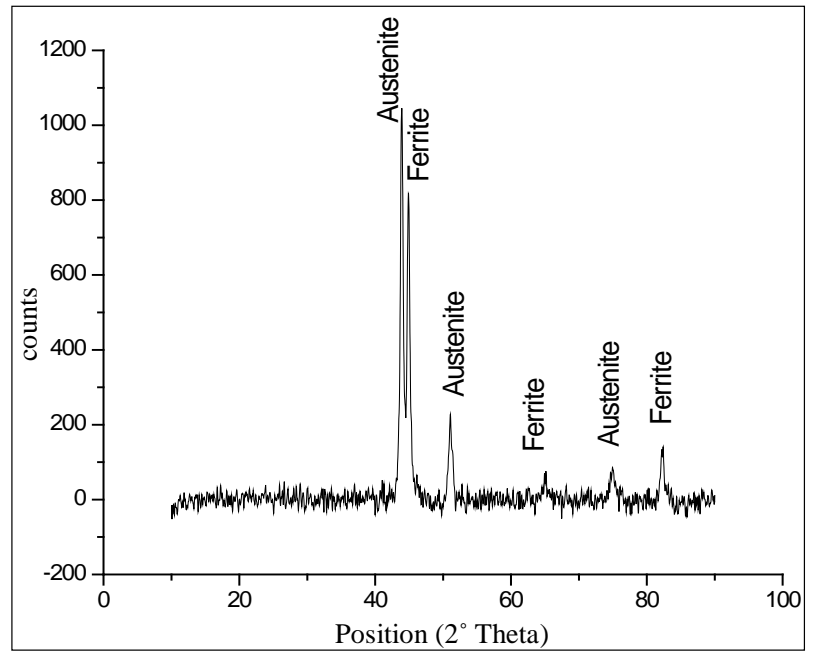

Figure 2. X-ray diffraction pattern of 2205 duplex stainless steel.

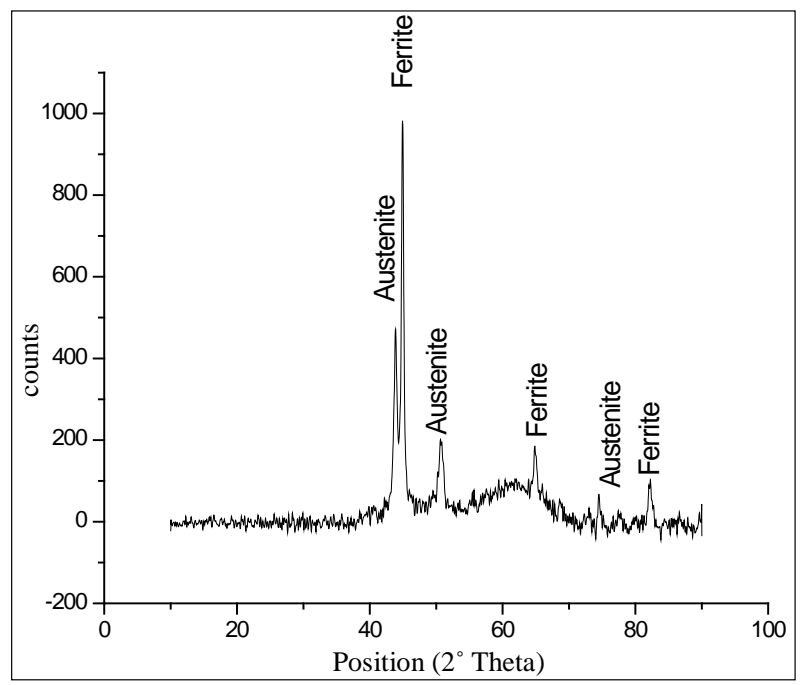

Figure 3. X-ray diffraction pattern of 2507 duplex stainless steel.

less steel, with austenite having the highest peak intensity.
The highest peak for 2507 (Figure 3) was the ferrite peak.

The SEM micrograph of as-received 2101 is presented in Figure 4 showing austenite in a ferritic matrix. The austenite particles showed irregular interfaces. The SEM image of 2205 duplex stainless steel is presented in Figure 5, showing austenite particles randomly dispersed in matrix of ferrite. Porosity was observed in the micrograph. Figure 6 presents the SEM micrograph of 2507 duplex stainless steel and alternate bands of austenite and ferrite were observed. Annealing twins were also observed. For all the samples two phases (austenite and ferrite) were observed. Inter-metallic phases were not observed.

\subsection{Potentiodynamic Tests}

When a metal is immersed in acidic solution, at equilibrium the rate of metal dissolution is equal to the rate of anodic reaction. Corrosion potential $\left(\mathrm{E}_{\mathrm{corr}}\right)$ is the potential associated with the equilibrium condition when the potential is made more positive than the open circuit potential, the current density for metal dissolution increases

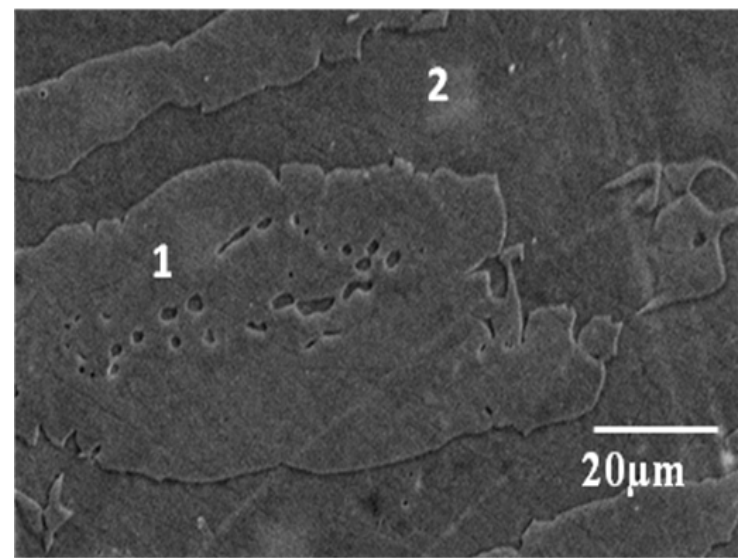

Figure 4. BSE-SEM micrograph of 2101 DSS showing ferrite (dark, 2), austenite (light, 1).

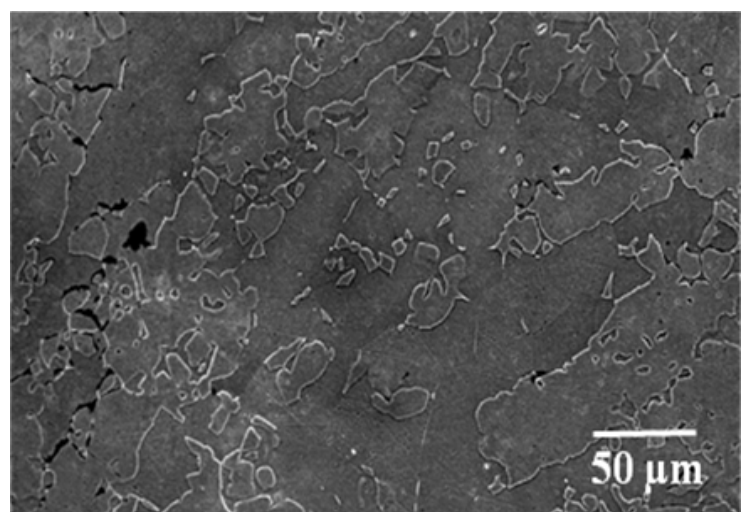

Figure 5. BSE-SEM micrograph of 2205 DSS showing ferrite (dark) and austenite (light). 


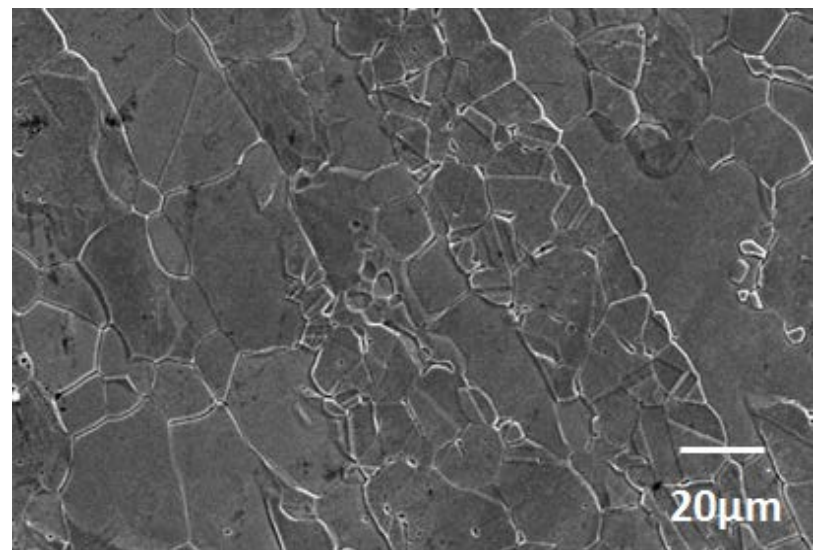

Figure 6. BSE-SEM micrograph of 2507 DSS showing ferrite (dark) and austenite (light).

steadily until it reaches a critical potential which is called primary passivation potential $\left(\mathrm{E}_{\mathrm{pp}}\right)$, and critical current density $\left(\mathrm{i}_{\text {crit }}\right)$ where the current density decreases to a lower value. The protective oxide layer result from the drop in the current density. Increased in the applied potential thickens the protective oxide layers. The current density associated with passing of the metal ions through the film becomes independent of the applied potential. Figure 7 showed the potentiodynamic curves obtained for the 3 samples in $1 \mathrm{M}$ sulphuric acid. The current density $\left(\mathrm{i}_{\text {crit }}\right.$ ) was higher for 2101 than for 2507 and 2205 while the most negative corrosion potential was observed in 2101; thus 2101 duplex stainless steel had lower corrosion resistance than 2205 and 2507 in $1 \mathrm{M}$ sulphuric acid this is probably due to the lower chromium and Mo content of the alloys. In sulphuric acid (Figure 7), there was an active-passive transition for 2205 and 2507 DSS. Passivity occurs in a shorter range of potentials in 2101 indicating a high tendency for localised corrosion. Increased in the current density of 2101 at very high potential is probably due to the oxygen evolution corresponding to the oxidation of water. The presence of wide passivation plateau was observed for 2205 and 2507. From the curve in Figure 7, it is evident that 2205 presents a good corrosion resistance comparable to that of 2101 and 2507. This is probably due to formation of a protective oxide film formed on the surface which is mainly chromium oxide. The potentiodynamic curves showed that 2205 and 2507 had the same tendency to form passive films, in both cases 2205 and 2507 experience pitting corrosion for potentials above $0.5 \mathrm{~V}$ vs SCE. At potential higher than the pitting potential an increased in current density with potential were observed, this is due to the breakdown of the passive films formed on the surface. These increased in the current density with potential occurs at a lower potential for 2101 than for 2205 and 2507 which could initiates an evolution of oxygen or start of pitting corrosion.
With the purpose of evaluating the effect of chloride on the corrosion behaviour of the samples understudy. Polarization curves were performed in $1 \mathrm{M}$ sulphuric acid contaminated with $1 \% \mathrm{NaCl}$. The result was shown in Figure 8. The potentiodynamic curves for 2101, 2205 and 2507 stainless steels are similar. Active dissolutions were observed in the samples. 2101 samples had higher current density than 2205 and 2507 . The pitting potentials are greater than $0.8 \mathrm{~V}$ vs SCE for the three samples. The curves show pseudo-passivity. An increased of current density with potential were observed.

Since corrosion potential is a mixed potential at which the absolute values of the anodic and cathodic currents are equal and considering that the cathodic process corresponds to hydrogen evolution, it is normal that the corrosion potential shows the tendency of the samples to corrode. The resistance to pitting attacks was governed mainly by chromium and molybdenum content. The volume fraction did not influence the corrosion resistance. All the steels understudy were duplex, their austenite and ferrite ratio were in the range of 70:30 which is acceptable.

\section{Conclusions}

X-Ray diffraction analyses, SEM image results and the

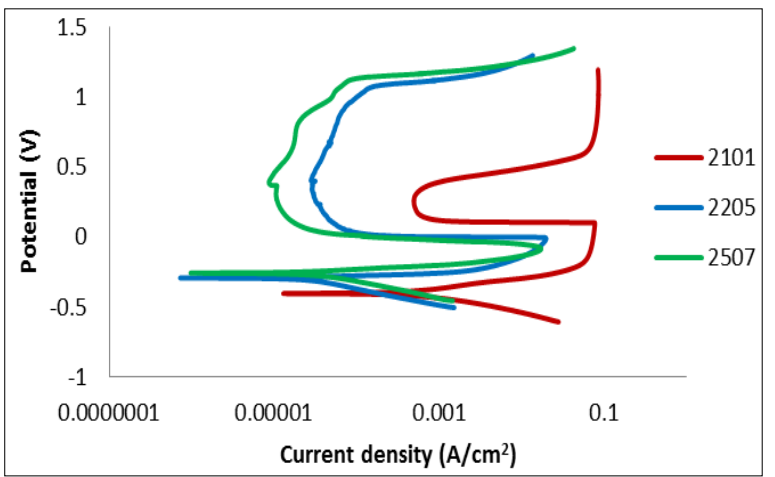

Figure 7. Potentiodynamic curves of 2101, 2205 and 2507 duplex stainless steels in $1 \mathrm{M} \mathrm{H}_{2} \mathrm{SO}_{4}$ at $25^{\circ} \mathrm{C}$.

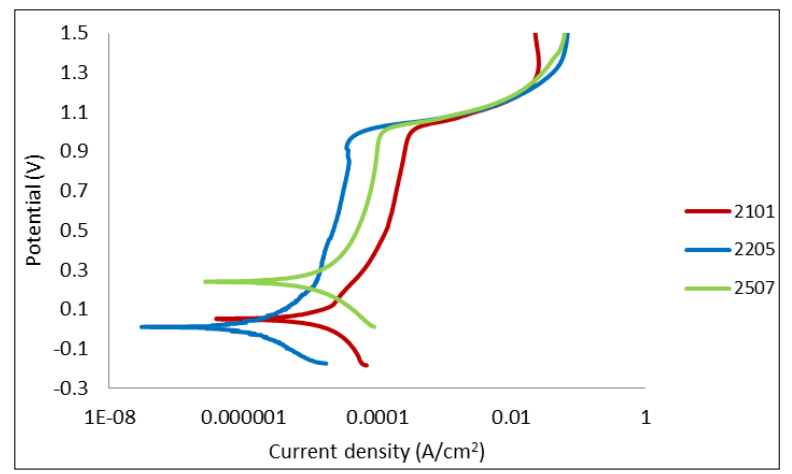

Figure 8. Potentiodynamic curves of 2101, 2205 and 2507 duplex stainless steels in $1 \mathrm{M} \mathrm{H}_{2} \mathrm{SO}_{4}+1 \% \mathrm{NaCl}$ at $25^{\circ} \mathrm{C}$. 
volume fraction results agreed together.

The elemental analyses of the phases showed that the element partitioned more into the phases that they promoted.

The corrosion resistance of 2101 is lower than 2205 and 2507 in $1 \mathrm{M}$ sulphuric acid and $1 \mathrm{M}$ sulphuric acid + $1 \%$ sodium chloride which could be due to the lower chromium and molybdenum content.

The similarity observed between the samples of 2205 and 2507 as compared to 2101 could be due to the contents nickel and molybdenum in the alloys.

The corrosion resistance 2507 in the studied media is better than all the other samples under study which could be a synergistic effect between chromium, molybdenum and manganese content.

\section{Acknowledgements}

This work was sponsored by African Materials and Engineering Network (AMSEN). Carnegie-IAS RISE Network.

\section{REFERENCES}

[1] H. D. Solomon and T. M. Devine, "Duplex Stainless Steels," Proceedings of Conference on Duplex Stainless Steels, Metal Park, 1983, pp. 693-756.

[2] F. M. Khoshnaw and R. H. Gardi, "Pitting Corrosion Resistance Determination of Duplex Stainless Steel by Using Critical Pitting Temperature Method,” 2006. http://www.stainless-steelworld.net/duplex/pittingcorrosion .asp

[3] J. Chance, W. Coop and K. J. Gradwell, "Structure Property Relationships in a 25Cr-7Ni-2Mo Duplex Stainless Steel Casting Alloy,” R. A. Lula, Ed., Proceedings of the Duplex Stainless Steel Conference, ASM Metals, Metal Park, 1983, p. 371.

[4] A. Desestret and J. Charles, "Stainless Steels," P. Lacombe, B. Baroux and G. Beranger, Eds., Les Editions de Physique, Paris, 1993, p. 2006.

[5] International Molybdenum Association, "Practical Guidelines for the Fabrication of Duplex Stainless Steels,” 2nd Edition, 2009. www.imoa.info

[6] J. M. Lardon, J. Charles, F. Dupoiron and J. C. Bavay, "Duplex Austenitic-Ferritic Stainless Steel, Mechanical Properties and Corrosion Resistance," Proceedings of the Conference on High Nitrogen Steels, Lille, 18-20 May 1988, p. 280.

[7] ASTM, “ASTM Designation: A923-06,” Standard Test Methods for Detecting Detrimental Intermetallic Phases in Duplex Austenitic/Ferritic Stainless Steel.

[8] J. K. L. Lai, K. W. Wong and D. J. Li, "The Effect of Solution Treatment on The Transformation Behaviour of Cold Rolled Duplex Stainless Steels,” Material Science and Engineering A, Vol. 203, No. 1-2, 1995 pp. 356-364. http://dx.doi.org/10.1016/0921-5093(95)09863-1

[9] S. A. Távara, M. D. Chapetti, J. L. Otegui and C. Manfredi, "Influence of Nickel on the Susceptibility to Corrosion Fatigue of Duplex Stainless Steel Welds,” International Journal of Fatigue, Vol. 23, No. 7, 2001, pp. 619626. http://dx.doi.org/10.1016/S0142-1123(01)00018-4 